\title{
Gestão: Organização, Qualidade e Bons Resultados
}

\author{
Ver artigo relacionado \\ na página 62
}

Hélio Castello ${ }^{1}$
A administração em saúde, isto é, de clínicas, hospitais ou serviços, vem sofrendo profunda transformação nos últimos anos, marcada pela sua profissionalização e por intenso trabalho de planejamento, formação de pessoal e busca pela qualidade e sustentabilidade financeira.

Sem dúvida alguma teremos que caminhar a passos largos nas próximas décadas para atingir o comportamento administrativo bem estruturado das grandes empresas.

O artigo de Cardoso et al.,1 publicado nesta edição da Revista Brasileira de Cardiologia Invasiva, demonstra a importância do planejamento orçamentário no gerenciamento do laboratório de hemodinâmica e põe em discussão fatos que habitualmente não fazem parte do dia a dia da maioria dos cardiologistas intervencionistas, apesar de estarem todos absolutamente envolvidos no assunto, fazendo deste uma leitura importante para a conscientização sobre o assunto.

As regras impostas pelas entidades de regulação, como a Agência Nacional de Vigilância Sanitária (Anvisa), somadas às exigências do mercado por qualidade crescente na assistência e maiores investimentos em infraestrutura, tecnologias e pessoal, fizeram com que nos preocupássemos cada vez mais com a gestão de nossos serviços.

Originalmente a ideia de criar uma simulação de um serviço de hemodinâmica para tentar dar subsídios administrativos que alertem vários intervencionistas para esse assunto é realmente muito boa e o uso de dados financeiros do Sistema Único de Saúde (SUS) faz com que as informações tenham características mais universais. No entanto, alguns pontos relevantes precisam ser discutidos, valorizados e individualizados para que possamos aplicar boa parte disso na realidade tão distinta de cada um de nós, principalmente no que se refere aos custos aqui minimizados com tributos e pessoal, entre outros, que fazem com que tenhamos uma ideia algo equivocada de sua lucratividade.
O planejamento orçamentário tem papel importante e deve ser amparado pelo planejamento estratégico, que programa ações para o crescimento, acompanhando tendências e necessidades do mercado, juntamente com ações de qualidade, aplicação de processos e protocolos, além de incansáveis treinamentos operacionais.

Os serviços de hemodinâmica deixaram de ser uma porta no fundo do corredor onde eram realizados exames diagnósticos de cateterismo para se tornarem centros de intervenções cardiovasculares, impulsionando os atendimentos não só da cardiologia como também de outras especialidades, como vascular e neurologia, entre outras. Assim, passaram a ter papel fundamental no posicionamento das instituições hospitalares no mercado de atendimento de alta complexidade.

Dessa forma, a análise da capacidade total do laboratório teria que ser mais arrojada, projetando utilização do equipamento de no mínimo 10 horas por dia (das 8 h00 às18h00), podendo chegar ao número estimado de pelo menos 200 procedimentos, sem contar aqueles realizados fora do horário comercial, pois o laboratório de hemodinâmica deve funcionar como uma unidade de emergência, com disponibilidade de 24 horas por dia e 7 dias por semana (24/7).

Além disso, diversos procedimentos diagnósticos e terapêuticos podem ser aí realizados, os quais irão impactar nas estimativas de faturamento e nas análises de custos e despesas, proporcionando aos gestores do hospital e do serviço argumentos que permitam projetar seus investimentos e suas ações de marketing.

Não há como não incluir nas despesas os custos com pessoal, que devem ser devidamente bem dimensionados, com plantonistas e folguistas, acrescidos de seus impostos, além dos tributos que incidem no faturamento, visto que a instituição hospitalar tem que ter conhecimento individual de cada setor para determinar seu futuro. E, a partir dessas informações, saber quais são os mais lucrativos ou os que fortale-

\footnotetext{
1 Hospital Bandeirantes - São Paulo, SP, Brasil.

Correspondência: Hélio Castello. Hospital Bandeirantes - Rua Galvão Bueno, 257 - Liberdade - São Paulo, SP, Brasil - CEP 01506-000

E-mail: heliocastello@terra.com.br

Recebido em: 11/3/2010 • Aceito em: 12/3/2010
} 
cem mais a marca da instituição, para ter subsídios de planejamento.

As estimativas de custos e despesas são facilitadas pela formatação e aplicação de processos e protocolos visando à previsibilidade dos gastos, e a partir disso avaliar a possível rentabilidade ou identificar as causas de prejuízos.

Mais que nos preocuparmos em definir termos correntes da linguagem administrativa, precisamos nos conscientizar que esses novos centros de intervenções, terceirizados ou próprios, funcionam dentro de instituições hospitalares complexas, públicas ou privadas, com maiores ou menores investimentos, porém, seja qual for o acordo entre as partes, devem ser encarados como unidades de negócios independentes e responsáveis por obrigações tributárias, manutenção de equipamentos, e gestão de qualidade e de pessoal, não podendo haver, dessa maneira, dicotomização, que impossibilitaria ao gestor do hospital uma avaliação mais criteriosa da influência desse segmento na totalidade de seu negócio.

Dentro da gestão de suprimentos temos nos deparado com obstáculos e desafios cada vez maiores, pois temos valores estáveis e congelados no faturamento por procedimento, porém a utilização única dos materiais, isto é, sem reprocessamento, faz com que tenhamos que fortalecer parcerias com fornecedores, programando compras de volumes maiores e conse- guindo preços mais atrativos, que viabilizem o uso sem macular a qualidade.

Por fim vale ressaltar a importância de que artigos com temas administrativos tenham espaço frequente em nossas revistas e jornais, pois nós, médicos, fomos colocados como pivôs da gestão, responsáveis pelo consumo de materiais e pelo operacional, porém sem termos o conhecimento básico para que ações de gerenciamento não influenciem negativamente na qualidade da assistência oferecida.

Devemos ainda lembrar que os serviços de hemodinâmica devem ser considerados unidades de negócios envolvidos na gestão global dos hospitais, porém com responsabilidades individuais de oferecer o melhor serviço com o menor custo, com responsabilidade social e com metas bem arrojadas de crescimento.

\section{CONFLITO DE INTERESSES}

O autor declarou inexistência de conflito de interesses relacionado a este manuscrito.

\section{REFERÊNCIA}

1. Cardoso CR, Prestes EP, Cardoso CO, Beulke R. Contribuição do planejamento orçamentário no gerenciamento do laboratório de hemodinâmica: simulação aplicada à gestão dos serviços de hemodinâmica. Rev Bras Cardiol Invasiva. 2010;18(1):62-7. 